UDC 665.775

Author: EVDOKIMOVA Natalya Georgiyevna, Doctor of Engineering, Associate Professor of Department «Chemical and Technological Processes», Ufa State Petroleum Technical University, Branch of the University in the City of Salavat; Gubkin St., 22B, Salavat, Bashkortostan, Russian Federation, ruskih1.r@yandex.ru;

Author: LUNEVA Natalya Nikolaevna, $\mathrm{PhD}$ in Economics, Ufa State Petroleum Technical University, Director of Branch of the University in the City of Salavat; Gubkin St., 22B, Salavat, Bashkortostan, Russian Federation, nat_luneva@mail.ru;

Author: EGOROVA Nadezhda Aleksandrovna, Graduate Student, Senior Lecturer of Department "Chemical and Technological Processes», Ufa State Petroleum Technical University, Branch of the University in the City of Salavat; Gubkin St., 22B, Salavat, Bashkortostan, Russian Federation, kushner-nadia@mail.ru;

Author: MAKHMUTOVA Alina Raufovna, Undergraduate of Department «Chemical and Technological Processes», Ufa State Petroleum Technical University, Branch of the University in the City of Salavat; Gubkin St., 22B, Salavat, Bashkortostan, Russian Federation, alina.ma@bk.ru; Author: BAYGUZINA Yulia Alfredovna, Undergraduate of Department «Chemical and Technological Processes», Ufa State Petroleum Technical University, Branch of the University in the City of Salavat; Gubkin St., 22B, Salavat, Bashkortostan, Russian Federation, yuly-3@yandex.ru;

Author: IMANGULOVA Elvina Alikovna, Student of Department «Chemical and Technological Processes», Ufa State Petroleum Technical University, Branch of the University in the City of Salavat; Gubkin St., 22B, Salavat, Bashkortostan, Russian Federation, enzhel7@mail.ru

\title{
THE SELECTION OF PRODUCTION TECHNOLOGY OF POLYMER- BITUMEN BINDERS AS AN INNOVATIVE NANOBINDERS USED IN ASPHALTIC CONCRETE PAVEMENT
}

\section{ExTENDED AbSTRACT:}

In recent years nanotechnology and nanomaterials have been used in various industries including road construction and road construction has reached a new level. Today it is one of the most priority field for the state. To increase the number of roads that would meet modern requirements is impossible without new technologies and materials. Bituminous materials are the example of such materials. They are typical oil nanodisperse systems, the properties of which are determined by the nanostructured particles of the dispersed phase and hydrocarbon dispersion medium. 
To expand the range of modern and promising binders, the aim of the research was to design a promising technology for the production of polymer-containing bituminous materials obtained by different technologies: modification by polymers of roadside bitumen, compounding of deeply oxidized bitumen with modified polymers, tar. The objects of the studies were the road bitumen, deepoxygenized bitumen, light and heavy tar. Butadiene-styrene thermoplastic elastomer DST-30-01 was used as polymer modifier that allows achieving the desired particle size of the dispersed phase and creates an additional nanophase of the polymer and thus provides the required performance.

The analysis of the properties of polymer-bitumen binders showed the advantage of the technology based on the compounding of deep-oxidized bitumen with modified polymer tar. There is an increase in the values of the maximum tensile force, cohesive and strength properties, adhesion index with a certain decrease in extensibility.

A promising technology for the production of polymer-bitumen binders as innovative nanobinders for asphaltic concrete pavement with improved quality indicators has been designed. The technology will expand the range of high-quality products needed in road construction and will provide the growth of technical and economic indicators of bitumen production.

Key words: bitumen, nanodisperse systems, polymeric-bituminous binder, plasticizer, modified tar, polymeric additives, compounding, technology, nanotechnology, physical and chemical properties.

\section{MACHine-REAdAble information ON CC-LiCENSES (HTML-CODE) In METAdATA OF THE PAPER}

$<$ a rel="license" href="http://creativecommons.org/licenses/by/4.0/" $><$ img alt="Creative Commons License" style="borderwidth:0" src="https://i.creativecommons.org/l/by/4.0/88x31.png" $/></ \mathrm{a}><$ br $/><$ span xmlns:dct="http://purl.org/dc/ terms/" href="http://purl.org/dc/dcmitype/Text" property="dct:title" rel="dct:type" $>$ The selection of production technology of polymer-bitumen binders as an innovative nanobinders used in asphaltic concrete pavement $</$ span $>$ by $<$ a xmlns:cc="http:// creativecommons.org/ns\#" href=". Nanotehnologii v stroitel'stve = Nanotechnologies in Construction. 2018, Vol. 10, no. 5, pp. 20-37. DOI: dx.doi.org/10.15828/2075-8545-2018-10-5-20-37." property="cc:attributionName" rel="cc:attributionURL"> Evdokimova N.G., Luneva N.N., Egorova N.A., Makhmutova A.R., Bayguzina Yu.A., Imangulova E.A. $</ a>$ is licensed under $\mathrm{a}<\mathrm{a}$ rel="license" href="http://creativecommons.org/licenses/by/4.0/" $>$ Creative Commons Attribution 4.0 International License $</ \mathrm{a}>$. $<$ br $/>$ Based on a work at $<$ a xmlns:dct="http://purl.org/dc/terms/" href="http://nanobuild.ru/en_EN/ nanobuild-5-2018/" rel="dct:source" $>$ http://nanobuild.ru/en_EN/nanobuild-5-2018/</a $>$. $<$ br $/>$ Permissions beyond the scope of this license may be available at $<$ a xmlns:cc="http://creativecommons.org/ns\#" href="ruskih1.r@yandex.ru" rel="cc: morePermissions">ruskih1.r@yandex.ru</a $>$. 


\section{References:}

1. Gaver S.V.,Urcheva YU.V., SyroezhkoA.M., Vasil'ev V.V. Vliyanie sovmestimosti neftyanyh bitumov i stirol-butadien-stirol'nyh polimerov na dispersnost' i ehkspluatacionnye harakteristiki polimerno-bitumnyh kompozicyj [Effect of compatibility between bitumen and styrene-butadiene-styrene polymers on dispersion and performance of polymer-bitumen composition]. Izvestiya SPbGTI (TU) [Bulletin of St PbSIT(TU)]. 2016, no. 36, pp. 68-71. (In Russian).

2. Rybachuk N.A. Problemy proizvodstva polimerno-bitumnyh vyazhushchih v dorozhnom stroitel'stve [Problems of polymer bitumen binders production in road construction]. Vestnik IrGTU [Scientific journal «Proceedings of Irkutsk State Technical University»], 2015, no. 5, pp. 98-105. (In Russian).

3. Evdokimova N.G. Razrabotka nauchno-tehnologicheskih osnov proizvodstvasovremennyh bitumnyh materialov kak neftjanyh dispersnyh sistem. Diss. ... d-ra tehn. nauk. [Development of the scientifically-technological of the bases of the production of contemporary bituminous materials as the petroleum dispersal systems. Thesis for Doctorate Degree]. Moscow, 2015, 417 p. (In Russian).

4. Khudyakova T.S., Masyuk A.F., Kalinin V.V. Osobennosti struktury i svojstv bitumov, modificirovannyh polimerami [Features of the structure and properties of bitumen modified with polymers]. Dorozhnaya tekhnika [Highroad Engineering], 2003, no. 7, pp. $174-$ 181. (In Russian).

5. Gohman L.M. Bitumy, polimerno-bitumnye vjazhushhie, asfal'tobeton, polimerasfal'tobeton: ucheb.-metod. Posobie [Bitumen, polymeric-bituminous binders, asphalt concrete, polymeric asphalt concrete. Study guide]. Moscow, «ECON-INFORM» Ltd., 2008, 117 p. (In Russian).

6. Doshlov O.I., Speshilov E.G. Polimerno-bitumnoe vyazhushchee - vysokotekhnologichnaya osnova dlya asfal'ta novogo pokoleniya [Polymer-bitumen binder-high-tech basis for new generation asphalt] Vestnik IrGTU [Scientific journal «Proceedings of Irkutsk State Technical University»], 2013, no. 6 (77), pp. 140-143.

7. Azunova R.R., Biglova R.Z., Talipov R.F., Cadkin M.A., Telyashev EH.G. Modificiruyushchaya dobavka dlya dorozhnogo bituma [Modifying additive for bitumen]. Neftegazovoe delo [Oil and Gas Business], 2013, no. 2, pp. 359-369. (In Russian).

8. Samsonov M.V. Modifikaciya svojstv dorozhny`x vyazhushhix materialov polimerami. Dis. kand. texn. nauk. [Modification of properties of the road binding materials with polymers. Thesis for PhD degree]. Moscow, 2015. 158 p. (In Russian).

9. Aminov Sh.X., Kut in Yu.A., Strugovecz I.B., Telyashev E`.G. Sovremenny`e bitumny`e vyazhushhie i asfal`tobetony`na ix osnove [Modern bituminous binders and asphalt concrete based on them]. Saint-Petersburg, JSC «Nedra», 2007. 336 p. (In Russian).

10. Tyukilina P.M., Gureev A.A. Zakonomernosti vliyaniya sostava plastifikatora na e`lastichnost`i kogezionnuyu prochnost` polimerno-bitumny`x vyazhushhix [Regularities of influence of plasticizer composition on elasticity and cohesive strength of polymer- 
bitumen binders]. Neftepererabotka i nefteximiya [Oil Refining and Petroleum Chemistry], 2018, no. 2, pp. 12-16. (In Russian).

11. Evdokimova N.G., Kim A.V., Egorova N.A. K voprosu o modificirovanii neftyanyh bitumov i opredelenii ih adgezionnyh svojstv [On the issue of modifying oil bitumen and determining their adhesion properties]. Neftegazovoe delo [Oil and Gas Business], 2016, Vol. 14, no. 4, pp. 91-96. (In Russian).

12. Evdokimova N.G., Makhmutova A.R., Kantimerova G.R., Kunakkulova E.M., Egorova N.A. Osobennosti povedeniya bituma, modificirovannogo polimernymi modifikatorami [Features of the behavior of bitumen modified with polymeric modifiers]. Neftegazovoe delo [Oil and Gas Business], 2017, Vol. 15, no. 3, pp. 95-99. (In Russian).

13. Leonenko V.V., Safonov G.A. Nekotorye aspekty modifikacii bitumov polimernymi materialami [Some aspects of bitumen modification with polymeric materials]. Himiya i tekhnologiya topliv i masel [Chemistry and Technology of Fuels and Oils], 2001, no. 5, p. 43. (In Russian).

14. Evdokimova N.G., Luneva N.N. O napravleniyax ispol'zovaniya dobavok razlichnoj prirody` dlya modificirovaniya svojstv bitumov [About the directions of use of additives of various nature for modifying of properties of bitumens]. Bashkirskij ximicheskij zhurnal [Bashkir chemistry journal], 2016, Vol. 23, no. 4, pp. 49-62. (In Russian).

15. Samsonov M.V. Modifikaciya svojstv dorozhnyh vyazhushchih materialov polimerami: Dis. kand. tekhn. Nauk [Modification of properties of road binders by polymers: Theiss for PhD Degree]. Moscow, RGU nefti i gaza imeni I.M. Gubkina [Gubkin Russian State University of Oil and Gas], 2015. 158 p. (In Russian).

16. Zaripov R.K., Mahmutov A.A., Mahmutov M.A., Kuzmichev S.P., Hazipov R.Z., Gorbachev N.G., Kosorenkov D.I., Lebedev I.N. Bitumno-polimernyj material i sposob ego polucheniya [Bitumen-polymer material and method to produce it]. Patent RF, no. 2132857, 2005. (In Russian).

17. Kremeneckaya E.V., Goryachev M.V., Igoshin YU.G., Korobicyn A.Yu. Polimerno-bitumnyj vyazhushchij material i sposob ego polucheniya [Polymer-bitumen binder and the method to produce it]. Patent RF, no.2011166, 2011. (In Russian).

18. Gluhovskoj V.S., Samocvetov A.R., Stepanov V.F., Sitnikova V.V., Brekhov P.P., Nechinennyj V.A., Dubina S.I., YAkimova L.A., YAkovleva T.A. Bitumnaya kompoziciya [Bituminous composition]. Patent RF, no. 2226203, 2004. (In Russian).

19. Volfson S.I., Xakimullin Yu.N.,Zakirova L.Yu., Xusainov A.D., Vol'fson I.S., Makarov D.B., Xozin V.G. Modifikaciya bitumov, kak sposob povy`sheniya ih e`kspluatacionny`h svojstv [Modification of bitumens as a way to increase their operational properties]. Vestnik texnologicheskogo universiteta [Herald of technological university], 2016, Vol. 19, no. 17, pp. 29-33. (In Russian).

20. Evdokimova N.G., Kunakkulova E.M. Sozdanie bloka polucheniya bitumno-polimerny`x mastik na osnove ustanovki proizvodstva bitumov OOO «Gazprom neftexim Salavat» [Creation of the block to produce bituminous and polymeric mastics on the basis of production equipment of bitumens of LLC Gazprom neftekhim Salavat]. Teoriya i praktika 
sovremennoj nauki [Theory and practice of modern science]. 2017, no. № 6 (24), pp. 459464. (In Russian).

21. Lyapin, A.Yu. Bitumno-polimernye materialy dlya dorozhnogo i grazhdanskogo stroitel'stva [Bituminous-polymeric materials for road and civil construction] Abstract of PhD thesis. Kazan, 2006. 23 p. (In Russian).

22. Samsonov M.V., Gureev A.A. Vozmozhnosti modificirovaniya svojstv dorozhnyh bitumov poliehtilenom i plastifikatorami [Feasibility of modifying properties of road asphalts with polyethelene and plasticizers]. Himiya i tekhnologiya topliv i masel [Chemistry and Technology of Fuels and Oils]. 2013, no. 5, pp. 34-37. (In Russian).

23. Rodionov B.N. Povyshenie ehffektivnosti i snizhenie stoimosti proizvodstva polimerbitumnyh vyazhushchih i polimerasfal'tobetonnyh smesej [Improving the efficiency and reducing the cost of production of polymer bitumen binders and polymerisation composites]. Stroitel'nye materialy, oborudovanie, tekhnologii XXI veka [Construction materials, the equipment, technologies of XXI century], 2015, no. 5, pp. 19-21. (In Russian).

\section{DeAr COLleagues!}

THE REFERENCE TO THIS PAPER HAS THE FOLLOWING CITATION FORMAT:

Evdokimova N.G., Luneva N.N., Egorova N.A., MakhmutovaA.R., Bayguzina Yu.A., Imangulova E.A. The selection of production technology of polymer-bitumen binders as an innovative nanobinders used in asphaltic concrete pavement. Nanotehnologii v stroitel'stve $=$ Nanotechnologies in Construction. 2018, Vol. 10, no. 5, pp. 20-37. DOI: dx.doi.org/10.15828/2075-8545-2018-10-5-20-37. (In Russian). 
Автор: ЕВДОКИМОВА Наталья Георгиевна, д-р. техн. наук, проф. каф. «Химико-технологические процессы», ФГБОУ ВО «Уфимский государственный нефтяной технический университет», филиал УГНТУ в г. Салавате; ул. Губкина, д. 22 Б, г. Салават, Башкортостан, Россия, 453200, ruskih1.r@yandex.ru;

Автор: ЛУНЕВА Наталья Николаевна, к.э.н., директор филиала ФГБОУ ВО «Уфимский государственный нефтяной технический университет» в г. Салавате; ул. Губкина, д. 22 Б, г. Салават, Башкортостан, Россия, 453200, Nat_luneva@mail.ru;

Автор: ЕГОРОВА Надежда Александровна, аспирант, ст. преподаватель каф. «Химикотехнологические процессы» филиала ФГБОУ ВО «Уфимский государственный нефтяной технический университет» в г. Салават; ул. Губкина, д. 22 Б, г. Салават, Башкортостан, Россия, 453200, kushner-nadia@mail.ru;

Автор: МАХМУТОВА Алина Рауфовна, магистрант каф. «Химико-технологические процессы»филиала ФГБОУ ВО «Уфимский государственный нефтяной технический университет» в г. Салават; ул. Губкина, д. 22 Б, г. Салават, Башкортостан, Россия, 453200, alina.ma@bk.ru; Автор: БАЙГУЗИНА Юлия Альфредовна, магистрант каф. «Химико-технологические процессы» филиала ФГБОУ ВО «Уфимский государственный нефтяной технический университет» в г. Салават; ул. Губкина, д. 22 Б, г. Салават, Башкортостан, Россия, 453200, yuly-3@yandex.ru; Автор: ИМАНГУ лОВА Эльвина Аликовна, студентка каф. «Химико-технологические процессы» филиала ФГБОУ ВО «Уфимский государственный нефтяной технический университет» в г. Салават; ул. Губкина, д. 22 Б, г. Салават, Башкортостан, Россия, 453200, enzhel7@mail.ru

\section{К ВЫБОРУ ТЕХНОЛОГИИ ПРОИЗВОДСТВА ПОЛИМЕРНО- БИТУМНЫХ ВЯЖУЩИХ КАК ИННОВАЦИОННЫХ НАНОСВЯЗУЮЩИХ ДЛЯ УСТРОЙСТВА АСФАЛЬТОБЕТОННЫХ ПОКРЫТИЙ}

АННОТАЦИЯ К СТАТЬЕ (АВТОРСКОЕ РЕЗЮМЕ, РЕФЕРАТ):

В последние годы нанотехнологии и наноматериалы стали использоваться в различных отраслях промышленности и, в том числе, в дорожном строительстве, а дорожное строительство вышло на новый уровень и является одним из приоритетных направлений государства. Увеличение доли автомобильных дорог, соответствующих современным нормативным требованиям, невозможно без применения новых технологий и материалов, к которым относятся битумные материалы, являющиеся типичными нефтяными нанодисперсными системами, свойства которых определяются наноструктурными частицами дисперсной фазы и углеводородной дисперсионной средой. 
Для расширения номенклатуры современных и перспективных вяжущих материалов целью исследований стала разработка перспективной технологии производства полимерсодержащих битумных материалов, полученных по разным технологиям: модифицирование полимерами битума дорожной марки, компаундирование глубокоокисленного битума модифицированным полимерами гудроном. В качестве объектов исследований использовали битум дорожной марки, глубокоокисленный битум, облегченный и утяжеленный гудрон. В качестве полимерного модификатора - дивинил-стирольный термоэластопласт марки ДСТ-30-01, который позволит достичь требуемых размеров частиц дисперсной фазы, создать дополнительную нанофазу из полимера и тем самым обеспечить требуемые эксплуатационные показатели.

Анализ свойств полимерно-битумных вяжущих показал преимущество технологии, основанной на компаундировании глубокоокисленного битума с модифицированным полимером гудроном. Происходит рост значений максимального усилия при растяжении, когезионных и прочностных свойств, показателя адгезии при некотором снижении растяжимости.

Разработана перспективная технология производства полимерно-битумных вяжущих как инновационных наносвязующих для устройства асфальтобетонных покрытий с улучшенными показателями качества, которая позволит расширить ассортимент востребованной в дорожном строительстве высококачественной продукции и рост технико-экономических показателей битумного производства.

Ключевые слова: битум, нанодисперсные системы, полимерно-битумное вяжущее, пластификатор, модифицированный гудрон, полимерные добавки, компаундирование, нанотехнология, физико-химические свойства.

DOI: dx.doi.org/10.15828/2075-8545-2018-10-5-20-37

МАШИНОЧИТАЕМАЯ ИНФОРМАЦИЯ о CC-ЛИЦЕНЗИИ в МЕТАДАННЫХ СТАТЬИ (НTML-КОД):

$<$ a rel="license" href="http://creativecommons.org/licenses/by/4.0/" ><img alt="Creative Commons License" style="borderwidth:0" src="https://i.creativecommons.org/l/by/4.0/88x31.png" $/></ \mathrm{a}><$ br $/><$ span xmlns:dct="http://purl.org/dc/ terms/" href="http://purl.org/dc/dcmitype/Text" property="dct:title" rel="dct:type">К выбору технологии производства полимерно-битумных вя- жущих как инновационных наносвязующих для устройства асфальтобетонных покрытий $</$ span $>$ by <a xmlns:cc="http://creativecommons.org/ns\#" href="Нанотехнологии в строительстве. - 2018. - Том 10, № 5. - С. 2037. - DOI: dx.doi.org/10.15828/2075-8545-2018-10-5-20-37." property="cc:attributionName" rel="cc:attributionURL" $>$ Eвд окимова Н.Г., Лунева Н.Н., Егорова Н.А., Махмутова А.Р., Байгузина Ю.А., Имангулова Э.А. </a > is licensed under a <a rel="license" href="http://creativecommons.org/licenses/by/4.0/" $>$ Creative Commons Attribution 4.0 International License $</$ a $>$. $<$ br / > Based on a work at <a xmlns:dct="http://purl.org/dc/terms/" href="http://nanobuild.ru/ru_RU/nanobuild-5-2018/" rel="dct:source" $>$ http://nanobuild.ru/ru_RU/nanobuild-5-2018/</a $>$. $<$ br $/>$ Permissions beyond the scope of this license may be available at $<$ a xmlns:cc="http://creativecommons.org/ns\#" href="ruskih1.r@yandex.ru" rel="cc:morePermissions" $>$ ruskih1 $. r @ y a n d e x . r u</ a>$. 
последние годы нанотехнологии и наноматериалы стали чаще использоваться в различных отраслях промышленности и, в том числе, в дорожном строительстве. В настоящее время дорожное строительство вышло на новый уровень и является одним из приоритетных направлений государства. Необходимость увеличения доли автомобильных дорог федерального и регионального значения, соответствующих современным нормативным требованиям, невозможно без применения новых технологий и материалов, к которым относятся битумные материалы, являющиеся типичными нефтяными нанодисперсными системами, свойства которых определяются наноструктурными частицами дисперсной фазы и углеводородной дисперсионной средой.

Инновационными наносвязующими для устройства асфальтобетонных покрытий являются полимерно-битумные вяжущие (ПБВ) $[1,2]$. Необходимо отметить, что введение полимерного модификатора загущает дисперсную систему битум, повышая при этом его температуру размягчения, придавая повышенную эластичность, улучшая низкотемпературные характеристики [3, 4]. Асфральтобетон на основе ПБВ обладает повышенной термостойкостью, пониженным значением хрупкости, улучшенной деформативной способностью, в итоге увеличивается срок службы асфальтобетонных покрытий [5-7].

Технология производства ПБВ заключается во введении в битум полимерной добавки при перемешивании в температурном интервале 150- $180^{\circ} \mathrm{C}$. Необходимым условием получения БПВ является способность полимера растворяться или набухать в дисперсионной среде битума.

Для производства ПБВ в основном используются битумы дорожных марок БНД по ГОСТ 22245-90 или по ГОСТ 33133-2014, полученные различными технологиями. В качестве полимера-модификатора практикуют введение различных материалов: каучуков, термопластичных полимеров, блоксополимеров, серосодержащих соединений, резиновую крошку и т.д. Наиболее часто применяются термо- 
эластопласты (ТЭП) - бутадиен-стирольный блоксополимер (СБС) [8]. Для обеспечения требуемого комплекса свойств в состав ПБВ вводится пластификатор (масло индустриальное И40, Азол 1101, Унипласт и др.), выбор которого определяется групповым химическим составом компонентов $[9,10]$. Необходимо отметить, что разработано значительное количество составов ПБВ по различным технологиям [11-19]. Однако исследования в этой области остаются актуальными, поэтому для расширения номенклатуры современных и перспективных вяжущих материалов целью исследований стала разработка перспективной технологии производства полимерсодержащих битумных материалов.

В работе были исследованы свойства полимерсодержащих битумных материалов, полученных по разным технологиям:

- модифицирование полимерами битума дорожной марки;

- компаундирование глубокоокисленного битума модифицированным полимерами гудроном.

В качестве объектов исследований использовались вещества, свойства которых представлены в табл. 1. Выбор полимерного модификатора марки ДСТ-30-01 обоснован тем, что, варьируя содержанием и соотношением полимера и пластификатора, можно достичь любых требуемых размеров частиц дисперсной фазы, создать дополнительную нанофазу из полимера и тем самым обеспечить требуемые эксплуатационные показатели для ПБВ (табл. 2).

При выборе концентрации ДСТ-30-01 руководствовались работами [19-22], где установлено, что при малых количествах (до 4\% ) полимер способен раствориться в масляной части битума и создавать нанодисперсную структуру битума. Поэтому содержание ДСТ-30-01 в битуме марки БНД 60/90 при реализации первой технологии составляло от 0,5 до $3,0 \%$ масс., процесс вели при температуре $160-180^{\circ} \mathrm{C}$. Физикохимические свойства полученных полимерсодержащих модифицированных битумов представлены в табл. 3 и на рис. 1.

Анализ физико-химических свойств модифицированного битума показал, что только при содержании 2\% масс. ДСТ-30-01 можно получить марку ПБВ 60. Кроме того, установлено, что с увеличением концентрации полимера в битуме происходит снижение значений растяжимости при $25^{\circ} \mathrm{C}$ с одновременным увеличением максимального усилия при растяжении, что связано с влиянием на этот показатель структурных особенностей полимера. 
Таблица 1

\section{Показатели качества объектов исследований}

\begin{tabular}{|c|c|c|}
\hline Наименование & Показатели качества & Значения \\
\hline \multirow{2}{*}{$\begin{array}{l}\text { Глубокоокислен- } \\
\text { ный битум }\end{array}$} & Глубина проникания иглы при $25^{\circ} \mathrm{C}, \mathrm{x} 0,1 \mathrm{мм}$ & 26 \\
\hline & Температура размягчения по кольцу и шару, ${ }^{\circ} \mathrm{C}$ & 87 \\
\hline \multirow[t]{3}{*}{ Гудрон 1} & Температура размягчения, ${ }^{\circ} \mathrm{C}$ & 24 \\
\hline & Вязкость условная при $80^{\circ} \mathrm{C}$, сек & \\
\hline & $\begin{array}{l}\text { Изменение температуры размягчения } \\
\text { после старения, }{ }^{\circ} \mathrm{C}\end{array}$ & 4 \\
\hline \multirow[t]{3}{*}{ Гудрон 2} & Температура размягчения, ${ }^{\circ} \mathrm{C}$ & 30 \\
\hline & Вязкость условная при $80^{\circ} \mathrm{C}$, сек & 96 \\
\hline & $\begin{array}{l}\text { Изменение температуры размягчения } \\
\text { после старения, }{ }^{\circ} \mathrm{C}\end{array}$ & 4 \\
\hline \multirow{9}{*}{$\begin{array}{l}\text { Битум марки } \\
\text { БНД } 60 / 90\end{array}$} & Глубина проникания иглы х 0,1 мм: & \\
\hline & при $25^{\circ} \mathrm{C}$ & 77 \\
\hline & при $0^{\circ} \mathrm{C}$ & 26 \\
\hline & Температура размягчения по кольцу и шару, ${ }^{\circ} \mathrm{C}$ & 47 \\
\hline & Растяжимость при $25^{\circ} \mathrm{C}, \mathrm{cm}$ & 46 \\
\hline & Изменение массы образца после старения, \% масс. & 0,78 \\
\hline & $\begin{array}{l}\text { Изменение температуры размягчения } \\
\text { после старения, }{ }^{\circ} \mathrm{C}\end{array}$ & 2 \\
\hline & Показатель адгезии, \% масс. & 67 \\
\hline & Показатель адгезии, № образца & 2 \\
\hline
\end{tabular}

Таблица 2

\section{Требования к ПБВ по ГОСТ 52056-2003}

\begin{tabular}{|c|c|c|}
\hline Показатель & ПБВ 60 & ПБВ 90 \\
\hline Температура размягчения, ${ }^{\circ} \mathrm{C}$ & не ниже 54 & не ниже 51 \\
\hline $\begin{array}{l}\text { Изменение температуры размягчения } \\
\text { после старения, }{ }^{\circ} \mathrm{C}\end{array}$ & не более 5 & не более 5 \\
\hline Растяжимость при $25^{\circ} \mathrm{C}$, см & не менее 25 & не менее 30 \\
\hline Эластичность, \% & не менее 80 & не менее 85 \\
\hline Глубина проникания иглы при $0^{\circ} \mathrm{C}, \mathrm{x}$ 0,1, мм & не менее 32 & не менее 40 \\
\hline Глубина проникания иглы при $25^{\circ} \mathrm{C}, \mathrm{x} 0,1, \mathrm{mм}$ & не менее 60 & не менее 90 \\
\hline Адгезия, № образца & № 2 & № 2 \\
\hline
\end{tabular}


Таблица 3

Физико-химические свойства битума марки БНД 60/90, модифицированного ДСТ-30-01

\begin{tabular}{|l|c|c|c|c|c|}
\hline \multicolumn{1}{|c|}{ Показатель } & \multicolumn{5}{|c|}{ Содержание ДСТ-30-01, \% масс. } \\
\cline { 2 - 6 } & $\mathbf{0 , 5}$ & $\mathbf{1}$ & $\mathbf{1 , 5}$ & $\mathbf{2}$ & $\mathbf{3}$ \\
\hline Температура размягчения, ${ }^{\circ} \mathrm{C}$ & 46 & 48 & 50 & 63 & 72 \\
\hline $\begin{array}{l}\text { Изменение температуры размягчения } \\
\text { после старения, }{ }^{\circ} \mathrm{C}\end{array}$ & 7 & 6 & 8 & -4 & -9 \\
\hline $\begin{array}{l}\text { Изменение массы образца } \\
\text { после старения, \% масс. }\end{array}$ & 0,58 & 0,62 & 0,32 & 0,29 & 1,47 \\
\hline $\begin{array}{l}\text { Глубина проникания иглы при } 0^{\circ} \mathrm{C}, \\
\text { х 0,1, мм }\end{array}$ & 40 & 34 & 25 & 30 & 30 \\
\hline $\begin{array}{l}\text { Глубина проникания иглы при } 25^{\circ} \mathrm{C}, \\
\text { х 0,1, мм }\end{array}$ & 36 & 41 & 45 & 63 & 63 \\
\hline Адгезия, \% масс. & 96 & 96 & 96 & 90 & 90 \\
\hline Адгезия, № образца & 1 & 1 & 1 & 2 & 2 \\
\hline
\end{tabular}

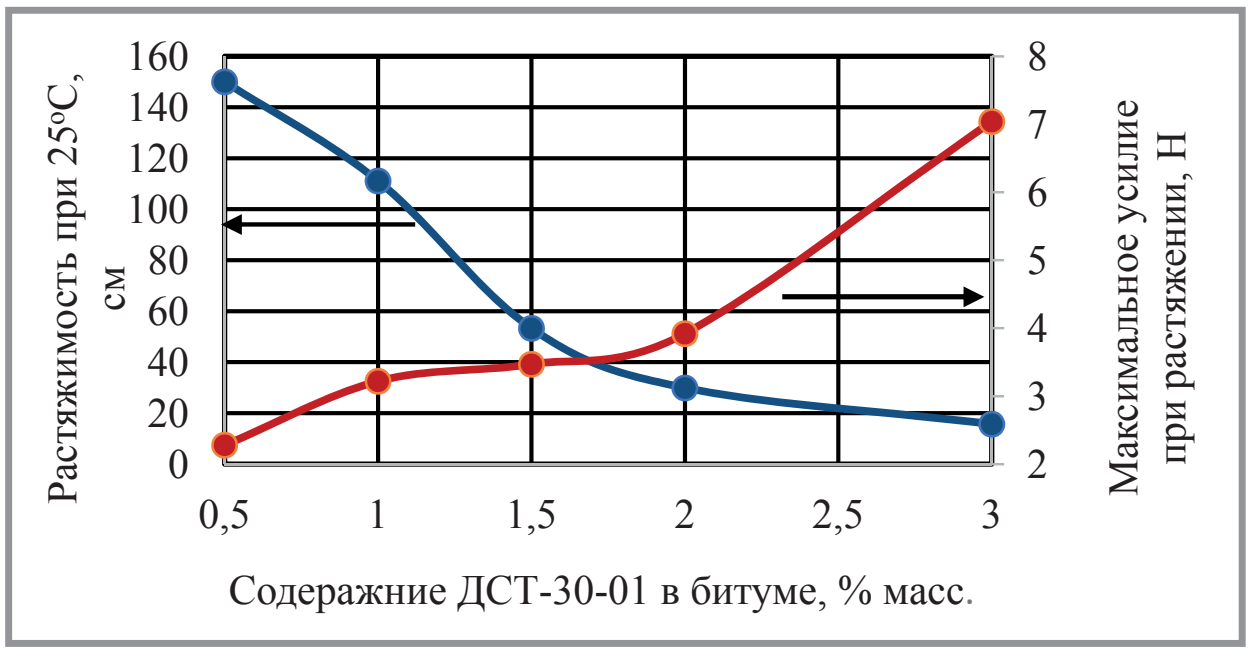

Рис. 1. Изменение растяжимости модифицированных битумов при $25^{\circ} \mathrm{C}$ от концентрации ДСТ-30-01

По второй технологии в качестве пластификатора для приготовления полимерного модификатора на основе ДСТ-30-01использовали два вида сырья: гудрон 1 с содержанием ДСТ-30-01 3, 5, 8\% масс. и гудрон 2 с содержанием ДСТ-30-01 1,5 и 3,0\% масс. 
Гудроны как вещества, содержащие в своем составе ароматические соединения, позволили не только сократить время приготовления полимерного модификатора по сравнению с использованием индустриального масла И40 (например, табл. 4) и оптимально вписаться в существующую технологическую схему производства битумов.

Глубокоокисленный битум компаундировали с модифицированными гудронами до получения битумов с пететрацией при $25^{\circ} \mathrm{C}$ в диапазоне (70-130) х 0,1 мм. В результате были получены образцы как ПБВ, так и модифицированного дорожного битума, соответствующего ГОСТ 33133-2014, показатели качества которых представлены в табл. 5 и 6 и на рис. 2-4.

Таблица 4

Показатели качества гудрона 1, модифицированного ДСТ-30-01

\begin{tabular}{|l|c|c|c|}
\hline \multirow{2}{*}{\multicolumn{1}{|c|}{ Показатели качества }} & \multicolumn{3}{c|}{ Содержание ДСТ- 30-01, \% масс. } \\
\cline { 2 - 4 } & $\mathbf{3}$ & $\mathbf{5}$ & $\mathbf{8}$ \\
\hline Температура размягчения, ${ }^{\circ} \mathrm{C}$ & 58,5 & 78,5 & 87,0 \\
\hline Глубина проникания иглы $25^{\circ} \mathrm{C}$, мм & 189 & 207 & 118 \\
\hline Время перемешивания, ч & 5 & 8 & 12 \\
\hline Время перемешивания в И40, ч & 12 & 18 & 24 \\
\hline
\end{tabular}

С увеличением содержания ДСТ-30-01 в гудроне 1 происходит рост значений максимального усилия при растяжении, который характеризует когезионные и прочностные свойства битума, при этом растет показатель адгезии, но несколько снижается растяжимость. При использовании в качестве пластификатора модифицированного ДСТ-30-01 гудрона 2 наблюдается обратная зависимость. Различие в свойствах объясняется групповым углеводородным составом гудронов. Более тяжелый гудрон 2 насыщен полициклоароматическими соединениями и смолами, которые позволяют увеличить прочность сцепления битума с минеральным материалом, а полимер в большей степени влияет на значения максимального усилия при растяжении, снижая его.

Анализ свойств битумов, полученных по двум технологиям, показывает преимущество технологии, основанной на компаундировании глубокоокисленного битума с модифицированным ДСТ-30-01 гудроном. 
таблица 5

Физико-химические свойства битума, полученного на основе глубокоокисленного битума и модифицированного ДСТ-30-01 Гудрона 1

\begin{tabular}{|c|c|c|c|c|c|c|}
\hline \multirow{2}{*}{ Показатели } & \multicolumn{6}{|c|}{ Содержание ДСТ-30-01 в гудроне, \% масс. } \\
\hline & 3 & 5 & 8 & 3 & 5 & 8 \\
\hline Температура размягчения, ${ }^{\circ} \mathrm{C}$ & 44 & 74 & 82 & 45 & 78 & 87 \\
\hline $\begin{array}{l}\text { Изменение температуры раз- } \\
\text { мягчения после старения, }{ }^{\circ} \mathrm{C}\end{array}$ & 1 & 4 & -3 & 2 & -3 & -11 \\
\hline $\begin{array}{l}\text { Изменение массы образца } \\
\text { после старения, \% масс. }\end{array}$ & 0,062 & 0,065 & 0,167 & 0,033 & 0,257 & 0,043 \\
\hline Эластичность при $25^{\circ} \mathrm{C}, \%$ & 64 & 90 & 95 & 94 & 94 & 97 \\
\hline $\begin{array}{l}\text { Глубина проникания иглы } \\
\text { при } 0^{\circ} \mathrm{C}, \text { х } 0,1, \text { мм }\end{array}$ & 28 & 33 & 32 & 45 & 44 & 42 \\
\hline $\begin{array}{l}\text { Глубина проникания иглы } \\
\text { при } 25^{\circ} \mathrm{C}, \mathrm{x} 0,1, \mathrm{mм}\end{array}$ & 81 & 93 & 88 & 128 & 107 & 118 \\
\hline Адгезия, № образца & 2 & 2 & 1 & 2 & 2 & 1 \\
\hline
\end{tabular}

Таблица 6

Физико-химические свойства битума, полученного на основе глубокоокисленного битума и модифицированного ДСТ-30-01 Гудрона 2

\begin{tabular}{|c|c|c|c|c|}
\hline \multirow{2}{*}{ Показатели } & \multicolumn{4}{|c|}{ Содержание ДСТ-30-01 в гудроне, \% масс. } \\
\hline & 1,5 & 3 & 1,5 & 3 \\
\hline Температура размягчения, ${ }^{\circ} \mathrm{C}$ & 45 & 54 & 49 & 58 \\
\hline $\begin{array}{l}\text { Изменение температуры } \\
\text { размягчения после старения, }{ }^{\circ} \mathrm{C}\end{array}$ & 4 & 0 & 2 & 0 \\
\hline $\begin{array}{l}\text { Изменение массы образца } \\
\text { после старения, \% масс. }\end{array}$ & 0,035 & 0,034 & 0,0086 & 0 \\
\hline Растяжимость при $25^{\circ} \mathrm{C}, \mathrm{cм}$ & 124 & 83 & 106 & 105 \\
\hline Эластичность при $25^{\circ} \mathrm{C}, \%$ & 30 & 81 & 40 & 87 \\
\hline $\begin{array}{l}\text { Глубина проникания иглы } \\
\text { при } 0^{\circ} \mathrm{C}, \mathrm{x} 0,1, \mathrm{Mм}\end{array}$ & 44 & 46 & 39 & 44 \\
\hline $\begin{array}{l}\text { Глубина проникания иглы } \\
\text { при } 25^{\circ} \mathrm{C}, \mathrm{x} 0,1, \mathrm{Mм}\end{array}$ & 77 & 85 & 103 & 108 \\
\hline Адгезия, № образца & 2 & 2 & 2 & 1 \\
\hline
\end{tabular}




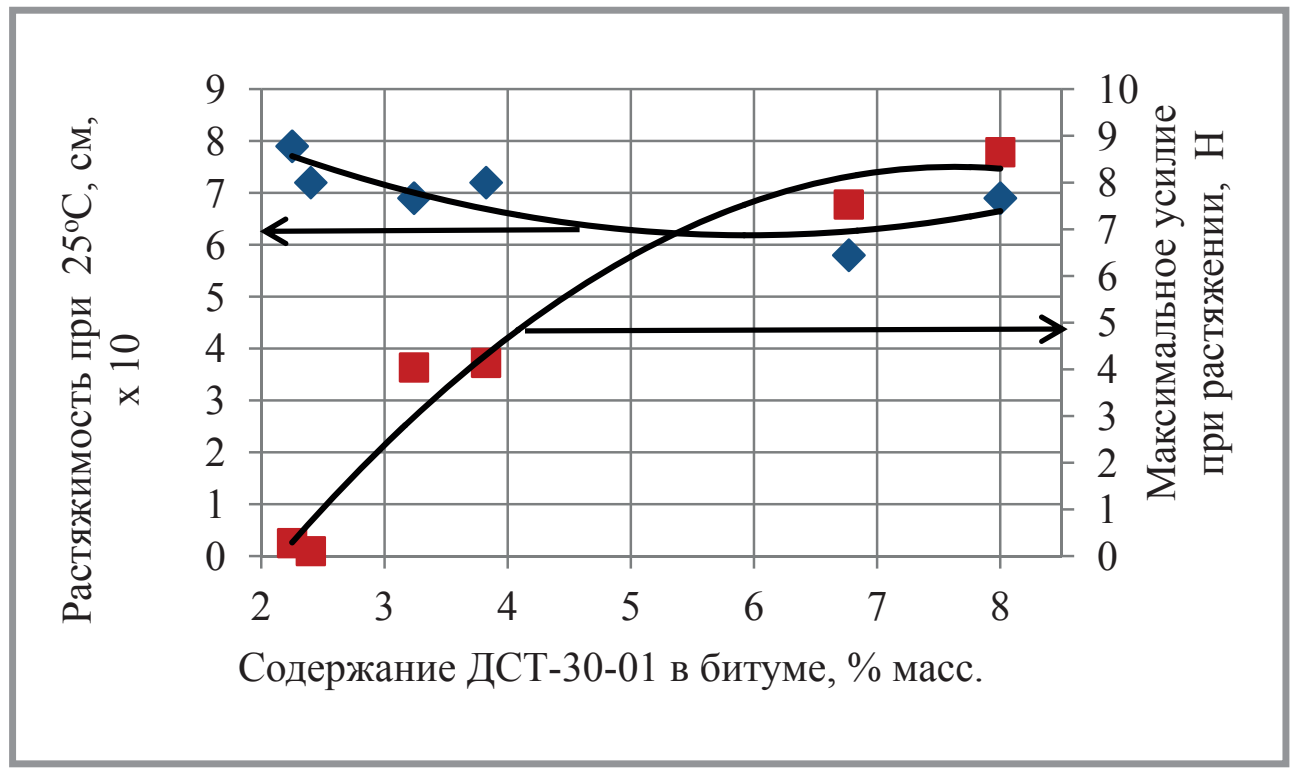

Рuc. 2. Зависимости растяжимости при $25^{\circ} \mathrm{C}$ и максимального усилия при растяжении полимерсодержащих битумов от содержания ДСТ-30-01 (пластификатор - Гудрон 1)

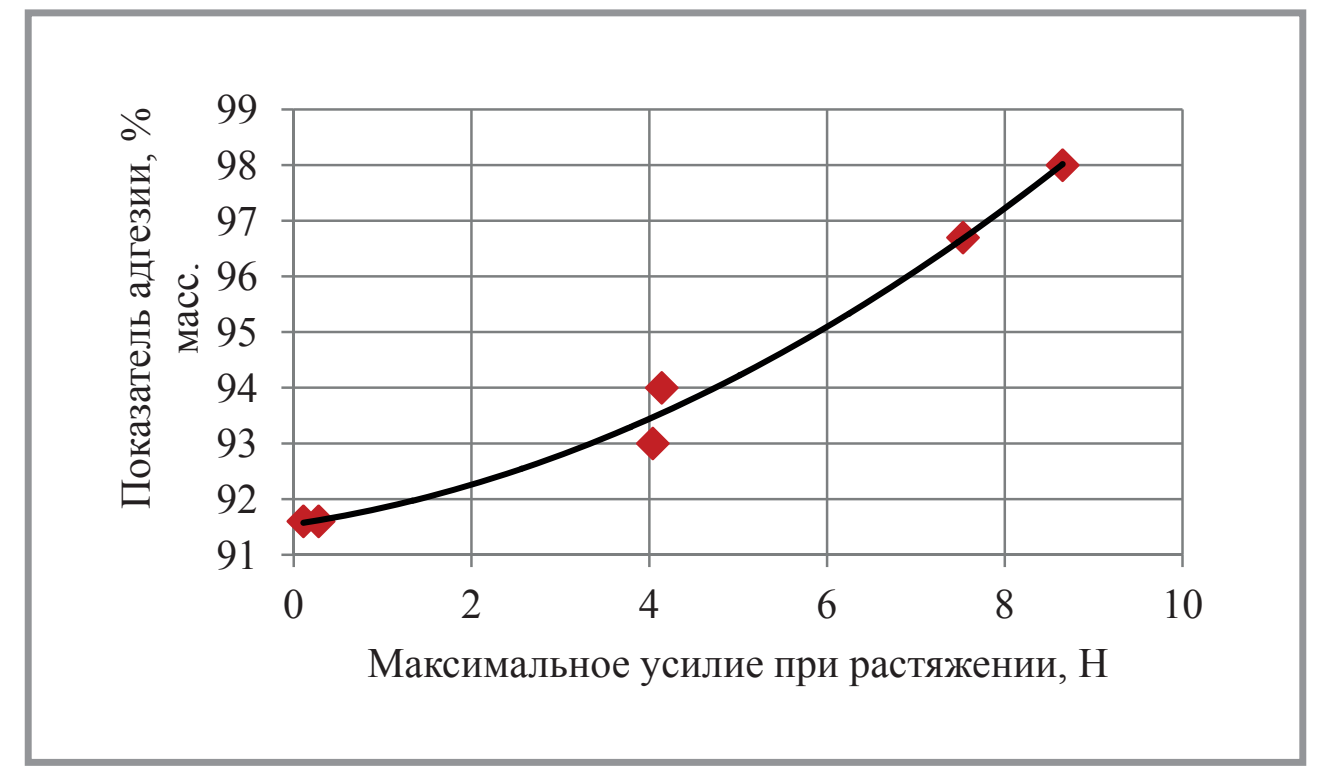

Рuc. 3. Показатель адгезии полимерсодержащих битумов от максимального усилия при растяжении (пластификатор Гудрон 1) 


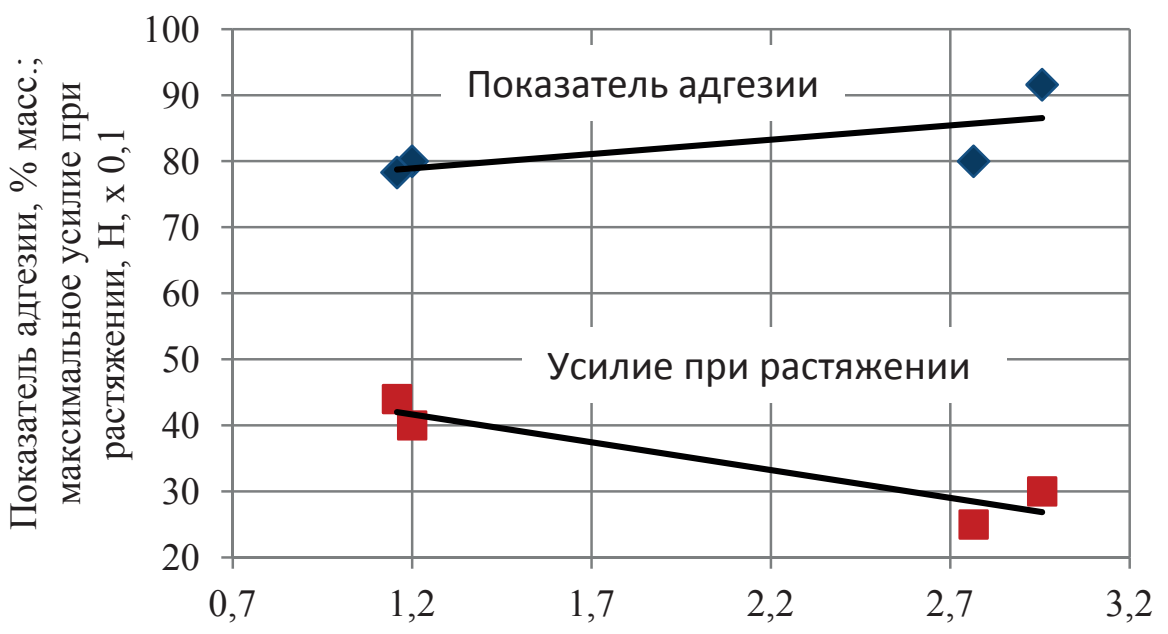

Содержание ДСТ-30-01 в битуме, \% масс.

Рuc. 4. Показатель адгезии и максимальное усилие при растяжении полимерсодержащих битумов от содержания ДСТ-30-01 (пластификатор - Гудрон 2)

Таблица 5

\section{Экономические показатели битумной установки при производстве ПБВ}

\begin{tabular}{|l|c|c|c|c|}
\hline \multicolumn{1}{|c|}{$\begin{array}{c}\text { Полимерный модификатор } \\
\text { на основе }\end{array}$} & \multicolumn{2}{|c|}{ Гудрона 1 } & \multicolumn{2}{c|}{ Гудрона 2 } \\
\hline \multicolumn{1}{|c|}{ Показатель / Марка ПБВ } & ПБВ 60 & ПБВ 90 & ПБВ 60 & ПБВ 90 \\
\hline $\begin{array}{c}\text { Содержание полимера в битуме, } \\
\text { \% масс. }\end{array}$ & 3,8 & 3,2 & $\mathbf{2 , 8}$ & 3,0 \\
\hline Объем выработки ПБВ, т/год & \multicolumn{3}{|c|}{35000} \\
\hline Капитальные затраты, тыс. руб. & \multicolumn{3}{|c|}{20000} \\
\hline $\begin{array}{l}\text { Себестоимость битума марок БНД, } \\
\text { тыс. руб./т }\end{array}$ & \multicolumn{3}{|c|}{13,02} \\
\hline Себестоимость ПБВ тыс. руб./т & 14,22 & 13,05 & 12,81 & 13,02 \\
\hline Прибыль, млн руб. & 114,10 & 124,60 & 112,00 & 113,75 \\
\hline Уровень рентабельности, \% & \multicolumn{3}{|c|}{25} \\
\hline
\end{tabular}


Для расширения ассортимента продукции и повышения техникоэкономических показателей битумной установки можно рекомендовать выпуск ПБВ 60 и ПБВ 90 на основе модифицированного гудрона 1 с 5\% масс. ДСТ-30-01 или гудрона 2 с 3\% масс. ДСТ-30-01. Экономические показатели битумной установки при производстве ПБВ в объеме 35 тыс. т/г показаны в табл. 5

Высокая стоимость полимерной добавки ДСТ-30-01 (130-160 тыс. руб./т) объясняет рост себестоимости готовой продукции по сравнению с битумом дорожной марки (7140 руб./т). Однако использование модифицированного полимером гудрона в качестве пластифицирующей добавки позволит значительно снизить себестоимость ПБВ по сравнению с приготовленным ПБВ по стандартной технологии с использованием индустриального масла (20000-22000 руб./т) [10, 14, 23].

Таким образом, разработана перспективная технология производства полимерно-битумных вяжущих как инновационных наносвязующих для устройства асфальтобетонных покрытий с улучшенными показателями качества, которая позволит расширить ассортимент востребованной в дорожном строительстве высококачественной продукции и улучшить рост технико-экономических показателей битумного производства.

\section{Библиографический список:}

1. Гавер С.В., Урчева Ю.В., Сыроежко А.М., Васильев В.В. Влияние совместимости нефтяных битумов и стирол-бутадиен-стирольных полимеров на дисперсность и эксплуатационные характеристики полимерно-битумных композиций // Известия СПбГТИ (ТУ). - 2016. - № 36. - С. 68-71.

2. Рыбачук Н.A. Проблемы производства полимерно-битумных вяжущих в дорожном строительстве // Вестник ИрГТУ. - 2015. - № 5. - С. 98-105.

3. Евдокимова Н.Г. Разработка научно-технологических основ производства современных битумных материалов как нефтяных дисперсных систем: Дис. ... докт. техн. наук. - М.: РГУ нефти и газа имени И.М. Губкина, 2015. - 417 с.

4. Худякова Т.С., Масюк А.Ф., Калинин В.В. Особенности структуры и свойств битумов, модифицированных полимерами //Дорожная техника. - 2003. - № 7. - С. 174-181.

5. Гохман Л.М. Битумы, полимерно-битумные вяжущие, асфальтобетон, полимерасфальтобетон. Учебно-методическое пособие. - М.: ЗАО «ЭКОН-ИНФОРМ», 2008. $117 \mathrm{c}$. 
6. Дошлов О.И., Спешилов Е.Г. Полимерно-битумное вяжущее - высокотехнологичная основа для асфальта нового поколения // Вестник ИрГТУ. - 2013. - № 6 (77). C. $140-143$.

7. Азунова Р.Р., Биглова Р.З., Талипов Р.Ф., Цадкин М.А., Теляшев Э.Г. Модифицирующая добавка для дорожного битума // Нефтегазовое дело. - 2013. - № 2. - С. 359-369.

8. Салсонов M.В. Модификация свойств дорожных вяжущих материалов полимерами: Дис. канд. техн. наук. - М.: РГУ нефти и газа имени И.М. Губкина, 2015. - 158 с.

9. Алинов Ш.Х., Кутьин Ю.А., Струговеи И.Б., Теляшев Э.Г. Современные битумные вяжущие и асфальтобетоны на их основе. - СПб.: ООО «Недра», 2007. - 336 с.

10. Тюкилина П.М., Гуреев А.А. Закономерности влияния состава пластификатора на эластичность и когезионную прочность полимерно-битумных вяжущих // Нефтепереработка и нефтехимия. - 2018. - № 2. - С. 12-16.

11. Евдокилова Н.Г., Ким А.В., Егорова Н.А. К вопросу о модифицировании нефтяных битумов и определении их адгезионных свойств // Нефтегазовое дело. - 2016. - Т. 14, № 4. - С. 91-96.

12. Евдокилова Н.Г., Махлутова А.Р., Кантилерова Г.Р. Кунаккулова Э.М., Егорова Н.А. Особенности поведения битума, модифицированного полимерными модификаторами // Нефтегазовое дело. - 2017. - Т. 15, № 3. - С. 95-99.

13. Леоненко В.В., Сафонов Г.А. Некоторые аспекты модификации битумов полимерными материалами // Химия и технология топлив и масел. - 2001. - № 5. - С. 43.

14. Евдокилова Н.Г., Лунева Н.Н. О направлениях использования добавок различной природы для модифицирования свойств битумов // Башкирский химический журнал. - 2016. - Т. 23, № 4. - С. 49-62.

15. Салсонов М.В. Модификация свойств дорожных вяжущих материалов полимерами: Дис. канд. техн. наук. - М.: РГУ нефти и газа имени И.М. Губкина, 2015. -158 с.

16. Зарипов Р.К., Махмутов А.А., Махмутов М.А., Кузмичев С.П., Хазипов Р.З., Горбачев Н.Г., Косоренков Д.И., Лебедев И.Н. Битумно-полимерный материал и способ его получения // Патент РФ № 2132857, 2005.

17. Креленецкая Е.В., Горячев М.В., Игошин Ю.Г., Коробицын А.Ю. Полимерно-битумный вяжущий материал и способ его получения // Патент РФ № 2011166, 2011.

18. Глуховской В.С., Салоиветов А.Р., Степанов В.Ф., Ситникова В.В., Брехов П.П., Нечиненный В.А., Дубина С.И., Якилова Л.А., Яковлева Т.А. Битумная композиция // Патент РФ № 2226203, 2004.

19. Вольфсон С.И., Хакилуллин Ю.Н., Закирова Л.Ю., Хусаинов А.Д., Вольфсон И.С., Макаров Д.Б., Хозин В.Г. Модификация битумов как способ повышения их эксплуатационных свойств // Вестник технологического университета. - 2016. - Т. 19 (17). C. 29-33.

20. Евдокилова Н.Г., Кунаккулова Э.М. Создание блока получения битумно-полимерных мастик на основе установки производства битумов ООО «Газпром нефтехим Салават» // Теория и практика современной науки. - 2017. - № 6 (24). -459-464 с.

21. Ляпин А.Ю. Битумно-полимерные материалы для дорожного и гражданского строительства: автореф. дис. ... канд. техн. наук. - Казань, 2006. - 23 с. 
22. Салсонов М.В., Гуреев А.А. Возможности модифицирования свойств дорожных битумов полиэтиленом и пластификаторами // Химия и технология топлив и масел. 2013. - № 5. - С. 34-37.

23. Родионов Б.Н. Повышение эффективности и снижение стоимости производства полимербитумных вяжущих и полимерасфальтобетонных смесей // Строительные материалы, оборудование, технологии XXI века. - 2015. - № 5. - С. 19-21.

\section{УВАЖАЕМЫЕ КОЛЛЕГИ!}

ПРИ ИСПОЛЬЗОВАНИИ МАТЕРИАЛА ДАННОЙ СТАТЬИ

ПРОСИМ ДЕЛАТЬ БИБЛИОГРАФИЧЕСКУЮ ССЫЛКУ НА НЕЁ:

Евдокилова Н.Г., Лунева Н.Н., Егорова Н.А., Махмутова А.Р., Байгузина Ю.А., Илиангулова Э.А. К выбору технологии производства полимерно-битумных вяжущих как инновационных наносвязующих для устройства асфальтобетонных покрытий // Нанотехнологии в строительстве. - 2018. - Том 10, № 5. - С. 2037. - DOI: dx.doi.org/10.15828/2075-8545-2018-10-5-20-37.

\section{DeAr COlleagues!}

THE REFERENCE TO THIS PAPER HAS THE FOLLOWING CITATION FORMAT:

Evdokimova N.G., Luneva N.N., Egorova N.A., Makhmutova A.R., Bayguzina Yu.A., Imangulova E.A. The selection of production technology of polymer-bitumen binders as an innovative nanobinders used in asphaltic concrete pavement. Nanotehnologii v stroitel'stve = Nanotechnologies in Construction. 2018, Vol. 10, no. 5, pp. 20-37. DOI: dx.doi.org/10.15828/2075-8545-2018-10-5-20-37. (In Russian).

Контактная

инфорлация: тел. 8-917-753-26-79, e-mail: ruskih1.r@yandex.ru 